\title{
DRAWBACK BEFORE THE WAVE?: PROTEST DECLINE DURING THE COVID-19 PANDEMIC
}

\author{
NILS W. METTERNICH \\ University College London, Department of Political Science
}

\begin{abstract}
We report an unprecedented decline in protest activity around the world during the Covid-19 pandemic. Using data from the Integrated Crisis Early Warning System from January 2018-April 2020, we calculate z-scores from average monthly and weekly protest activity in countries around the world. Comparing continents, we find an especially pronounced decline of protest in European and Asian countries. We provide four conjectures about the implications this decline in protest can have on future protest behavior.
\end{abstract}

\section{INTRODUCTION}

2019 was marked by commentators as the year of protests. Indeed, protests in Lebanon, Hong Kong, Iraq, Chile, and many other places highlighted the known importance of protest to bring about political change by challenging politicians and their policies. Protests in 2019 for fundamental changes in climate policies also showed the ability to raise political awareness within societies and the vital function protests fulfil in democracies. Indeed, the general consensus in the political science literature is that protest is an important part of functioning democratic societies Kitschelt, 1986; Jenkins, Wallace and Fullerton, 2008; Della Porta, 2014) and it is therefore not surprising that the right to peacefully protest and demonstrate is enshrined in almost every democratic constitution. Protests have the capacity to solve collection action problems (Tilly, 2003), create protest cascades (Granovetter, 1978; Yin, 1998), and ultimately help to bring political change (Tarrow, 2011; Chenoweth and Stephan, 2011, Leventoğlu and Metternich, 2018: Tertytchnaya, 2019) that is especially feared by autocratic leaders that tend to respond with repression against dissent (Davenport, 2007; Davenport and Moore, 2012).

This research report provides insights into an unprecedented fall in protest activity around the world in the context of the SARS-CoV-2 pandemic especially in Asian and European countries

E-mail address: n.metternich@ucl.ac.uk.

Date: May 5, 2020.

Note: These are preliminary research results and are subject to updates in the near future. Nils W. Metternich acknowledges support from the Economic and Social Research Council (ES/L011506/1). 
which initially saw the greatest number of positive SARS-CoV-2 cases and responded with social distancing measures. We caution that some of the decline in protest can stem from a decline in reporting activity, but the differences across continents suggest that government and self-imposed social distancing play an important part in the decline of protest. The following section outlines the data and measurements used to document the decline in protest, while the last section will provide four conjectures about the implication this decline might have on future protest behavior.

\section{Technical Report}

In this report, we use data from the Integrated Crisis Early Warning System (Boschee et al., 2015) which automatically codes worldwide news reports from various international outlets. News articles are automatically coded by the BBN ACCENT event coder (developed by Raytheon BBN Technologies) based on BBN SERIF, a natural language analysis program. Events are coded based on Conflict and Mediation Event Observations (CAMEO) (Gerner et al. 2002), which provides ontologies and dictionaries for international conflict events. In CAMEO there are twenty top-level categories for events of which 'Protest' is the one we are focusing on. BBN Technologies claims that it can code protest events with 84.4 percent precision. Each CAMEO event in ICEWS includes, among other variables, actor (e.g. source and target), event type, date, and location information (e.g. latitude/longitude) which are leveraged in this report. Events pertaining to purely United States domestic affairs are excluded from ICEWS as it received Office of Naval Research Funding.

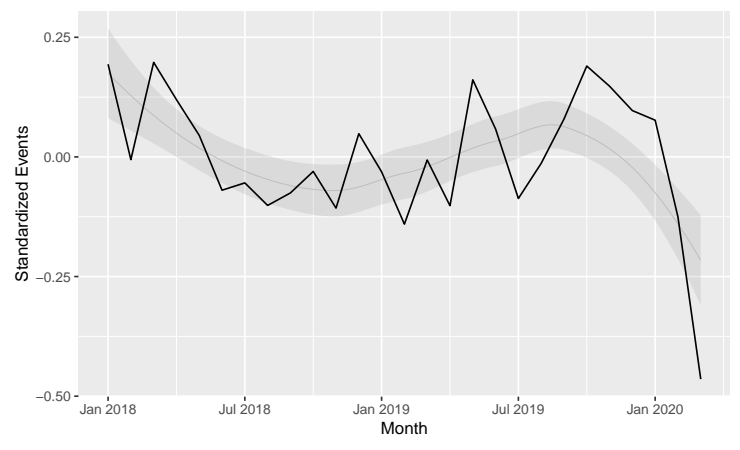

(A) Global monthly

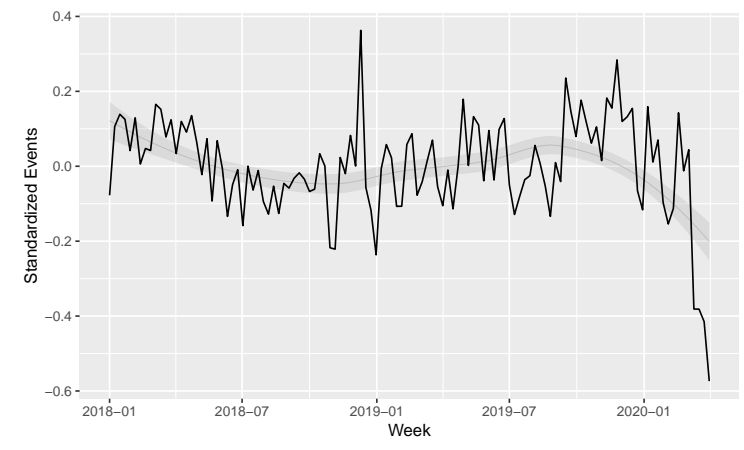

(B) Global weekly

FIGURE 1. Global average of protest activity measured on the monthly (left panel) and weekly (right panel) level. Protest activity is measured as the number of days in a month/week, ICEWS reports any protest activity for a country. Number of reporting days is z-standardized on the respective country level to enable comparison across countries. Black line represents the mean across all countries. Grey line pertains to a smoothed average with confidence bands. 
We extract all protest events from ICEWS between 1 January 2018 and 30 April $2020(\approx 61 \mathrm{k}$ events) and create a cross-sectional time-series with all countries that have experienced protest during the observation period. ICEWS is known to include duplicate events (Wang et al., 2016) (e.g. multiple news organizations reporting same events) and imprecise location coding. Hence, for our two measurements of protest, we calculate a) the number of days per month and b) the number of days per week any protest was reported in a country. Thus, the maximum number of protest days in the monthly measure is 31 and and in the weekly measure 7 . We argue that this is a fairly conservative measure based on the ICEWS data.

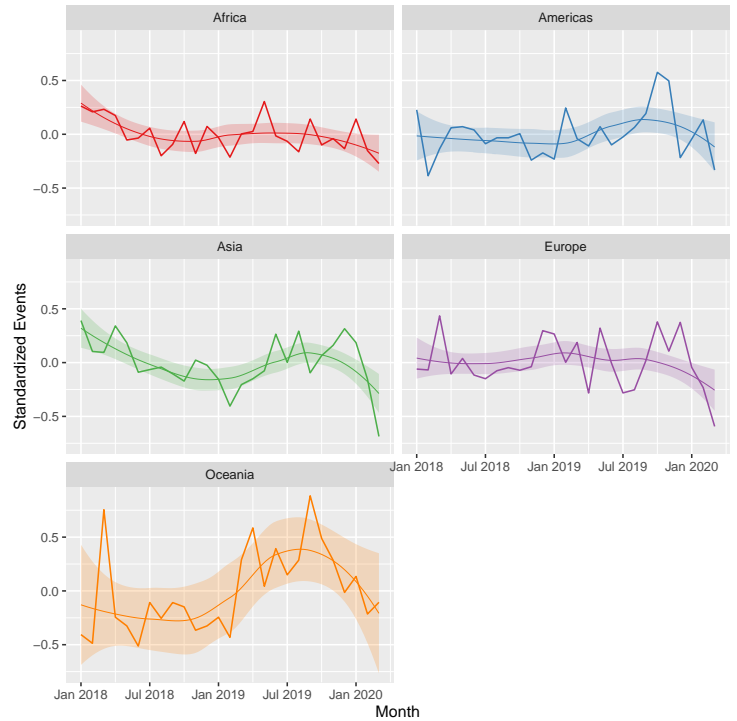

(A) Continents monthly

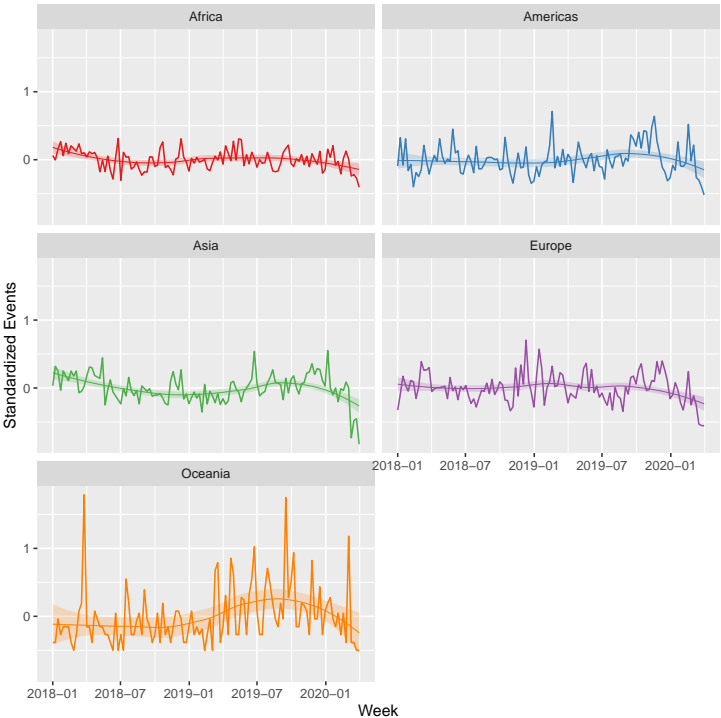

(в) Continents weekly

Figure 2. Continent averages of protest activity measured on the monthly (left panel) and weekly (right panel) level. Protest activity is measured as the number of days in a month/week, ICEWS reports any protest activity for a country. Number of reporting days is z-standardized on the respective country level to enable comparison across countries. Bold lines represent the mean across all countries in a continent. Thin lines pertain to a smoothed average with confidence bands.

To account for the fact that countries have vastly different baselines of protest events, we $\mathrm{z}$ standardize each of the respective country time series. This allows us to compare country variation in protest on a similar scale. Figure 1 provides the monthly and weekly global average protest z-score (black line). In addition, Figure 1 includes a smoothed average estimate (GAM based) with confidence bands (grey). In the left panel, the monthly average z-score drops to almost -0.5, while the weekly z-score average drops to almost -0.6 (right panel). This means that in the observed time period, the average global protest events is at its lowest recorded value. 
Figure 2 provides the average z-scores for all continents 1 . In the monthly protest measure (left panel), it becomes clear that countries in Asia and Europe (which had among the most stringent social distancing measures) have seen on average the greatest decline in protest. The weekly protest measure suggests (right panel) less differences in continent differences as more recent weeks (last weeks of April 2020) seen increasingly social distancing measures and SARS-CoV-2 cases in the Americas and Africa. The weekly Figure 2 shows a particular steep decline in protest activity in Asia, particularly driven by India in the later part of April.

In interpreting these findings, it is important to be aware of potential limitations in the underlying data. First, the observed decline in protest activity could stem from a decline in reporting about protests as reporting focuses on SARS-CoV-2. Second, reporting could be limited as journalists themselves adhere to self-distancing and are not able to report on protests. Third, governments might have greater ability to suppress reporting during state of emergencies. We attempt to address these concerns in future versions of this report.

\section{Conjectures}

We conclude this report by highlighting four possible protest developments that might arise in the near future or are already observable. First, we can expect an increase of protests to reestablish or defend the right to peacefully assemble, which has been diminished by government restrictions. These protests can entail mixed motives and general suspicion of government policies. Second, where opportunistic autocratic regimes try to take advantage of state of emergencies to foster policies beyond the public health, protests to re-establish the right for peaceful assembly will be met with repressive force leading to violent clashes. Third, movements that have relied on protest to gain public support will be hampered in their ability to leverage 'street power' as government social distancing rules and individual health concerns increase the costs of joining public gathering. Finally, SARS-CoV-2 related economic, social, health related consequences can create new and exacerbate existing societal cleavages and inequalities leading to greater political mobilization (Vogt, 2019) Where this political mobilization is met with government repression, escalation to violence can be expected (Dudouet, 2013). Political mobilization in less repressive regimes can lead to peaceful protest, opposition support, and shifting electoral behavior.

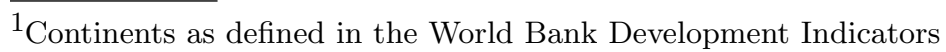




\section{REFERENCES}

Boschee, Elizabeth, Jennifer Lautenschlager, Sean O'Brien, Steve Shellman, James Starz and Michael Ward. 2015. "ICEWS Coded Event Data.".

URL: https://doi.org/10.7910/DVN/28075

Chenoweth, Erica and Maria J Stephan. 2011. Why civil resistance works: The strategic logic of nonviolent conflict. New York: Columbia University Press.

Davenport, Christian. 2007. "State Repression and Political Order." Annual Review of Political Science 10(1):1-23.

Davenport, Christian and Will H Moore. 2012. "The Arab Spring, Winter, and Back Again?(Re) Introducing the Dissent-Repression Nexus with a Twist." International Interactions 38(5):704713.

Della Porta, Donatella. 2014. Mobilizing for democracy: Comparing 1989 and 2011. Oxford: OUP Oxford.

Dudouet, Vronique. 2013. "Dynamics and factors of transition from armed struggle to nonviolent resistance." Journal of Peace Research 50(3):401-413.

Gerner, Deborah J, Philip A Schrodt, Omür Yilmaz and Rajaa Abu-Jabr. 2002. "Conflict and mediation event observations (CAMEO): A new event data framework for the analysis of foreign policy interactions." International Studies Association, New Orleans .

Granovetter, Mark. 1978. "Threshold models of collective behavior." American Journal of Sociology 83(6):1420-1443.

Jenkins, J Craig, Michael Wallace and Andrew S Fullerton. 2008. "A social movement society?: A cross-national analysis of protest potential." International Journal of Sociology 38(3):12-35.

Kitschelt, Herbert P. 1986. "Political opportunity structures and political protest: Anti-nuclear movements in four democracies." British journal of political science 16(1):57-85.

Leventoğlu, Bahar and Nils W Metternich. 2018. "Born Weak, Growing Strong: Anti-Government Protests as a Signal of Rebel Strength in the Context of Civil Wars." American Journal of Political Science 62(3):581-596.

Tarrow, Sidney G. 2011. Power in Movement: Social Movements and Contentious Politics. New York: Cambridge University Press.

Tertytchnaya, Katerina. 2019. "Protests and Voter Defections in Electoral Autocracies: Evidence From Russia." Comparative Political Studies OnlineFirst. 
Tilly, Charles. 2003. The politics of collective violence. Cambridge: Cambridge University Press.

Vogt, Manuel. 2019. Mobilization and Conflict in Multiethnic States. Oxford: Oxford University Press.

Wang, Wei, Ryan Kennedy, David Lazer and Naren Ramakrishnan. 2016. "Growing pains for global monitoring of societal events." Science 353(6307):1502-1503.

Yin, Chien-Chung. 1998. "Equilibria of collective action in different distributions of protest thresholds." Public Choice 97(4):535-567. 